\title{
Uma Nota Sobre Efeitos de Gastos Públicos Federais Sobre o Crescimento da Economia Brasileira
}

\author{
Soraia Santos da Silva*, Divanildo Triches ${ }^{\dagger}$
}

\author{
Conteúdo: 1. Introdução; 2. Gastos Públicos e Crescimento Econômico; 3. Análise e \\ Descrição dos Resultados da Relação Entre Gastos Públicos e Crescimento \\ Econômico; 4. Conclusões; A. Apêndice. \\ Palavras-chave: Gasto Público, Crescimento Econômico, Teste de Causalidade, Cointegração. \\ Códigos JEL: F20, F21, F23, G10.
}

0 artigo tem o objetivo de analisar os efeitos dos gastos governamentais sobre o produto da economia brasileira ao longo do período de 1980 a 2005, identificando a contribuição de algumas categorias de gastos públicos sobre o crescimento do produto no Brasil. Para isso, foram investigadas as séries dos componentes das despesas públicas federais, em particular, tanto por grupo como por função. Os procedimentos metodológicos usados basearam-se nos testes de Dickey-Fuller Aumentado (DFA) e Phillips e Perron (PP), teste de Causalidade de Granger e o método de Cointegração de Engle e Granger e Johansen. Os resultados dos testes de raiz unitária mostraram que as séries estudadas de produto e despesas públicas são I(1). A maioria dos pares de variáveis mostrou causalidade no sentido de Granger fluindo dos componentes dos gastos públicos para o produto. As exceções ficaram por conta dos gastos com defesa e segurança nacional e educação. Da mesma forma, esses tipos de despesas não se mostraram estatisticamente significantes nas estimações. Entretanto, comunicação, saúde e saneamento, energia e recursos minerais e transporte foram as categorias de gastos públicos que mostraram relevância empírica na composição das despesas públicas. As evidências mostram que essas despesas podem ser consideradas como gastos produtivos. Para uma dada quantidade de fatores privados, melhores estradas, portos, ferrovias, comunicação, saúde e

\footnotetext{
* Doutora em Economia pela Universidade Federal do Rio Grande do Sul (UFRGS). Professora e pesquisadora da Universidade Federal da Grande Dourados (UFGD). E-mail: soraiasantos@ufgd.edu.br .

†Doutor em Economia pela Universidade Federal do Rio Grande do Sul (UFRGS). Professor e pesquisador no Programa de Pós-Graduação em Economia da Universidade do Vale do Rio dos Sinos, PPGE/UNISINOS. E-mail: divanildo@pq. cnpq.br, divanildot@unisinos.br.
} 
saneamento implicam uma maior produtividade desses fatores e, consequentemente, elevando o produto final.

The article has the goal to analyze the effects of the government expenses about the product of the Brazilian economy along the period from 1980 to 2005, identifying the contribution of some categories of public expenses about the growth of the product in Brazil. For that, the components of public federal expenses time series were investigated, in particular, in both ways by group and function. The methodological procedures were based on tests Augmented Dickey-Fuller and Phillips and Perron, Granger Causality test, Engle and Granger Cointegration and Johansen Cointegration method. The results of unit root tests showed that the series studied of product and public expenses are I(1). Most pairs of variables showed Granger causality flowing from the components of the public expenses to the product. The exceptions stayed due to the expenses with defense and national safety and education. In the same way, these kinds of expenses did not show statistically significant in the estimation. However, communication, health and basic sanitation, energy and mineral resources and transport were the categories of public expenses that showed empiric relevance in the composition of the public expenses. The evidences showed that these expenses can be considered as productive expenses. For a given quantity of private, best factors highways, harbors, railroads, communication, health and basic sanitation imply a larger productivity of these factors and increasing the final product.

\section{INTRODUÇÃO}

Existe uma literatura teórica e empírica extensa que trata da relação entre o tamanho do governo, no que tange ao nível de despesas públicas, e o crescimento econômico do País. Isso é uma questão de particular interesse para os países em desenvolvimento, os quais necessitam de um crescimento econômico mais acelerado, com a finalidade de elevar o nível de bem estar. Em geral, os gastos públicos em infraestrutura afetam o retorno dos insumos privados, estimulando o investimento e o emprego e, consequentemente, o crescimento do produto da economia. As atividades governamentais podem elevar o nível do produto total de forma direta ou indireta por meio da interação com o setor privado.

No Brasil, estudos recentes exploram efeitos do capital público sobre o crescimento econômico e a produtividade. Eles mostram, no entanto, que ao longo da década de oitenta o país apresentou taxas de crescimento econômico baixo devido à baixa capacidade de inversões por parte do governo. Já, a partir da segunda metade dos anos 90 , têm-se levantado alguns questionamentos voltados a fato de que a política fiscal teria dado muita ênfase às metas de superávits primários, para o pagamento da dívida interna brasileira. Como consequência, os investimentos em setores primordiais em infraestrutura, tais como: transporte, energia, telecomunicações e saneamento, teriam sido relativamente baixos, implicando também em baixas taxas de crescimento da economia brasileira.

Além disso, o Brasil tem uma elevada carga tributária suportada pelos consumidores e pelas empresas, cerca de 38\% e 34\% do PIB em 2007 e 2008, respectivamente. Segundo a Secretaria da Receita Federal, a carga tributária brasileira é maior que a do México (20\%), Turquia (24\%), Estados Unidos (27\%), Suíça (29\%), Argentina $(29,3 \%)$ e Canadá (32\%). Essa elevada carga tributária causa distorções 
graves no comportamento do consumo e dos investimentos privados, pois, em média, metade do preço dos bens de consumo é destinada ao pagamento de tributos. $O$ aumento da tributação, combinado com baixos investimentos públicos em infraestrutura, tem efeitos negativos sobre o crescimento econômico e sobre o emprego, principalmente, quando há a necessidade de investimentos públicos em setores que trariam uma maior produtividade para a atividade econômica do país.

A literatura mostra que os gastos públicos podem elevar o crescimento econômico, tornando o setor privado mais produtivo. Os serviços de infraestrutura, como, por exemplo, o de transportes, telecomunicações, energia e a formação de um sistema legal e de segurança - que preservam o direito de propriedade e a defesa nacional - são alguns exemplos que servem de insumo básico para o setor privado.

Por sua vez, o financiamento dos gastos públicos via impostos pode provocar distorções e ineficiência na alocação de recursos, reduzindo ou eliminado os efeitos positivos dessas externalidades positivas. ${ }^{1}$ Para Barro e Martins (1990), os impactos dos gastos públicos sobre o crescimento econômico dependem das características dos gastos, por exemplo, a formação de capital fixo pelo setor público deveria contribuir de forma positiva para o aumento da produção. Já, as despesas públicas em consumo, em geral, tenderiam retardar o crescimento da economia.

No entanto, os estudos empíricos não encontram evidências consistentes de uma relação significante entre os gastos do governo e o crescimento econômico, seja numa direção positiva, seja negativa. Isso pode ser em decorrência das diferenças na estrutura econômica entre os países, das abordagens metodológicas empregadas e da classificação dos gastos públicos. Nesse sentido, o artigo tem como objetivo analisar os efeitos dos gastos governamentais sobre o produto da economia brasileira ao longo do período de 1980 a 2005, identificando a contribuição de algumas categorias de gastos públicos sobre o crescimento do produto no Brasil. Para tanto, o texto está organizado, além desta introdução, como segue: a seção 2 descreve resumidamente as relações teóricas e desenvolve e discute a especificação básica do modelo a ser estimado. A análise empírica e os resultados são traçados na seção 3. Por fim, a seção 4 apresenta as considerações finais e as conclusões.

\section{GASTOS PÚBLICOS E CRESCIMENTO ECONÔMICO}

A investigação empírica da relação gastos públicos e crescimento econômico baseou-se na estrutura teórica de crescimento econômico endógeno de Barro (1990). Esse modelo foi ampliado de maneira que o setor público oferte serviços ao setor privado. Isto é, o modelo considera que os serviços públicos desempenham a função de insumos no processo produtivo, ou seja, aumentando a produtividade do setor privado. Portanto, é dessa forma que os serviços públicos produzem ligações potencialmente positivas entre o governo e o crescimento econômico.

A abordagem metodológica procura examinar e identificar a ligação entre gastos públicos e o crescimento econômico na economia brasileira. As despesas públicas foram classificadas de duas formas: a) por grupo e b) por função. Os gastos públicos por grupo são divididos em: despesas correntes, que incluem despesas com salário, encargos sociais, outros gastos em bens e serviços, exceto pagamento de juros e encargos da dívida, e despesas de capital, que incluem os investimentos públicos, isto é, a acumulação ou a produção de bens duráveis.

Alguns gastos públicos por função foram escolhidos como variáveis explicativas, por exemplo, gasto em: comunicação, defesa nacional e segurança pública, educação, saúde e saneamento, energia e recursos minerais, transporte e assistência e previdência social. Em geral, os componentes dos gastos públicos são selecionados de acordo com a possibilidade de estarem associados a um crescimento econômico.

\footnotetext{
${ }^{1}$ A concepção mais geral é de que gastos públicos, principalmente, em capital humano e em infraestrutura podem estimular o crescimento, porém seu financiamento, por meio de tributação, implica efeitos contrários, desestimulando os investimentos privados.
} 
Segundo Cândido e José (2001), os serviços de infraestrutura (por exemplo; transporte, telecomunicações e energia) e os serviços de preservação dos direitos de propriedade e do cumprimento da lei, por meio dos serviços de defesa nacional e segurança pública, são atividades que devem aumentar a eficiência da atividade privada. ${ }^{2}$

As despesas públicas em educação podem, segundo Barro (1990), ser consideradas como gastos que aumentam o produto nacional, pois seria um investimento em capital humano. Já os gastos com saúde e saneamento estão ligados mais à questão de aumento do bem estar social e ao impacto de políticas de desenvolvimento econômico. A importância dos gastos com saúde pode ser também vista a partir do momento em que esses gastos favorecem a qualidade da força de trabalho. Por fim, a inclusão do componente assistência e previdência social deve-se ao fato de que a participação dessa categoria cresceu muito rapidamente na participação dos gastos totais públicos, a partir de 1988. A inclusão dessas categorias de gastos públicos é identificar a importância de sua composição sobre o produto. Como não existem resultados definitivamente conclusivos nos modelos teóricos e empíricos sobre tais relações, procuraram-se evidências e resultados nas estimações sobre tais impactos. ${ }^{3}$ Inicialmente, estimaram-se os efeitos dos gastos agregados e, em seguida, os efeitos específicos das categorias de gastos. ${ }^{4}$ Os modelos estimados assumem a seguinte forma funcional das equações (1) e (2):

$$
\ln Y=\ln a+\alpha_{1} \ln \text { descorry }+\alpha_{2} \ln \text { descapy }+\epsilon_{t}
$$

$$
\ln Y=\ln \alpha_{0}+\alpha_{1} \ln e d u c y+\alpha_{2} \ln c o m y+\alpha_{3}
$$

$\ln$ sausy $+\alpha_{4} \ln d e s f y+\alpha_{5} \ln$ enermy $+\alpha_{6} \ln$ transpy $+\alpha_{7} \ln$ assprevy $+\epsilon_{t}$

onde todas as variáveis foram transformadas em logaritmo, de forma que os coeficientes estimados permitem que sejam interpretados em termos de elasticidade. A variável dependente é o produto interno bruto (PIB) do Brasil em termos reais. O conjunto de variáveis explicativas inclui:

i) Descorry: despesas públicas da União correntes em proporção ao PIB;

ii) Descapy: despesas públicas da União com capital em proporção do PIB;

iii) Educy: proporção dos gastos da União com educação sobre o PIB;

iv) Comy: proporção dos gastos da União com comunicação sobre o PIB;

v) Sausy: proporção dos gastos da União com saúde e saneamento sobre o PIB;

vi) Defsy: proporção dos gastos da União com defesa nacional e segurança pública sobre o PIB;

vii) Enermy: proporção dos gastos da União com energia e recursos minerais sobre o PIB;

viii) Transpy: proporção dos gastos da União em transporte sobre o PIB;

ix) Assprevy: proporção dos gastos da União em assistência e previdência social. O termo $\epsilon_{t}$ no final de cada equação de regressão é o erro aleatório, com média zero e variância constante. ${ }^{5}$

\footnotetext{
${ }^{2}$ Alguns estudos que tratam dessa temática sobre a economia brasileira são Cândido e José (2001), Ferreira (1996), Ferreira e Malliagros (1998), Herrera e Blanco (2006), Lledó e Ferreira (1997), Mazoni (2005), entre outros.

${ }^{3}$ Barro (1990) mostra que existe um tamanho ótimo do governo de forma que há um limite de expansão nos gastos públicos, pois, a partir de certo nível, os gastos públicos teriam um efeito predominantemente negativo sobre o crescimento econômico.

${ }^{4}$ Enders (1995) e Harris (1995) descrevem com mais detalhamento o procedimento de cointegração segundo Engle e Granger (1987), Granger et alii (1998), Johansen (1988) e Johansen e Juselius (1990). As estimações foram efetuadas usando o programa Eviews 4.0

${ }^{5}$ Todas as variáveis foram deflacionadas pelo IGP-M. Nas estimações das equações (1) e (2), que consideram os gastos agregados e sua composição, utilizaram-se as séries anuais compreendendo o período de 1980 a 2005 . Inicia-se a investigação estimando-se
} 


\section{ANÁLISE E DESCRIÇÃO DOS RESULTADOS DA RELAÇÃO ENTRE GASTOS PÚBLICOS E CRESCIMENTO ECONÔMICO}

Analisando as séries de tendências extraídas a partir do Filtro de Hodrick e Prescott, pode-se observar o comportamento de longo prazo das séries de gastos públicos. ${ }^{6}$ As despesas correntes da União apresentaram uma tendência crescente de logo prazo, com poucas oscilações durante o período de 1980 a 2005. Já as despesas com capital da União mostraram maiores flutuações assumindo uma tendência decrescente entre 1992 e 2005. Os gastos públicos totais mostraram uma clara tendência crescente no componente das despesas não financeiras obrigatórias a partir de 1986. Isso foi em decorrência do aumento da parcela de gastos com pessoal, seguridade social e de transferências constitucionais a estados e municípios, que, somadas, passaram de $55 \%$ do total das despesas não financeiras em 1986 para $80 \%$ em 2001.

Com isso, houve um decréscimo correspondente na participação dos gastos com investimento e em outros gastos correntes, que representavam em 2001 somente $20 \%$ do total das despesas não financeiras. Além disso, os investimentos do governo cresceram na década de 80 à taxa de $2,4 \%$ ao ano. No conjunto, a taxa de investimento agregada no setor público a preços constantes declinou de $6,9 \%$ em 1990 para 3,8\% do PIB em 2000. Essa redução se deu em função principalmente da redução dos estoques de financiamento domésticos e externos.

Os gastos com comunicação caíram continuamente de 1980 até 1993, mostrando um decréscimo aproximadamente de $90 \%$ nesse período. A partir de 1994, essa categoria de gastos voltou a crescer na participação dos gastos totais, mostrando em 2002 um aumento de mais de $200 \%$. Na administração seguinte, que se iniciou em 2003, voltaram a ser destinados menos recursos a essa categoria de despesas públicas, porém ficando em um patamar acima do nível mínimo atingido em 1993. Os gastos com defesa e segurança mostraram-se voláteis, crescendo lentamente até 1998, quando, a partir desse ano, passou a assumir taxas decrescentes. Os gastos com educação também mostraram crescimento contínuo até 1998, apesar da volatilidade, quando passa a assumir uma tendência decrescente até 2005 . É relevante observar que, depois de uma queda de $41 \%$ entre 1990 e 1993, os gastos com educação cresceram em 1994, mantendo-se uma estabilidade até 1998 num patamar mais elevado de gastos.

Os gastos com energia e recursos minerais apresentaram uma tendência decrescente até 1994; nesse ano, os gastos reduziram-se cerca de $90 \%$, relativamente aos gastos realizados em 1989. Essa categoria passou a apresentar uma tendência positiva, culminando em um pico em 2003 e voltando a decrescer em seguida. Os gastos com saúde e saneamento cresceram continuamente até 1991, apresentando uma estabilidade nas despesas com saúde até 2005. Já os gastos com transporte assumiram uma tendência decrescente ao longo de todo o período analisado. Os gastos com a assistência e previdência social cresceram continuamente sua participação sobre os gastos totais, assumindo um valor de aproximadamente de $30 \%$ dos gastos em 2005 .

A análise das tendências mostra que parte significativa das despesas em infraestrutura tem decaído ao longo do período. De forma agregada, as despesas com capital assumiram uma tendência decrescente. Apesar da volatilidade, observou-se também que as despesas desagregadas por tipos de gastos em infraestrutura apresentaram, em geral, uma tendência decrescente. Os setores de comunicação e de energia exibiram uma recuperação a partir de 1994, mostrando-se uma tendência positiva, porém um crescimento a taxas cada vez menores.

Os resultados dos testes de raiz unitária ( $D F$ e $A D F)$ mostraram evidências fortes de que as séries que representam as despesas públicas e o produto brasileiro são não estacionárias em nível, ou seja,

a tendência de longo prazo das séries, por meio da aplicação do Filtro de Hodrick e Prescott. Em seguida, testa-se a ordem de integração de cada uma das séries, pelos testes Dickey e Fuller (DF), Dickey e Fuller Ampliado (ADF) e após os testes de Causalidade e o método cointegração de Engle e Granger e Johansen.

${ }^{6}$ A figura A1, no Apêndice, apresenta as estimativas do Filtro de Hodrick e Prescott das tendências das séries da composição dos gastos e do produto interno bruto brasileiro no período de 1980 a 2005. 
são integradas de primeira ordem, I(1). Esses resultados foram observados nas três versões dos testes de estacionaridade: com constante, com constante e tendência e sem constante e sem tendência. $O$ número de defasagem nos testes foi escolhido segundo os critérios SBC e AIC. Tomando as séries em primeira diferença, os resultados indicaram estacionaridade das séries.

Para identificar a direção de causalidade entre as séries, realizaram-se os testes de causalidade de Pairwise de Granger nas séries do produto e dos componentes da despesa pública no período de 1980 a 2005. Os resultados dos testes não apontaram qualquer relação de causalidade bidirecional entre as variáveis. A maioria dos pares de variáveis mostrou causalidade fluindo dos componentes dos gastos públicos para o produto em níveis de significância de $5 \%$ e $10 \%$. As variáveis despesas com energia e recursos minerais e com transporte mostraram significância de $5 \%$ no teste. E as variáveis despesas com assistência social, com comunicação e com saúde e saneamento mostraram significância de 10\%. As exceções ficaram por conta dos gastos públicos com defesa e segurança e com a educação. Nesses casos, não se observa qualquer relação causal no sentido Granger. Os critérios de informação de Akaike e o critério bayesiano de Schwartz foram utilizados para identificar o número de defasagem apropriado.

Agregando os gastos em despesas correntes e em despesas com capital, foi possível verificar significância entre despesas correntes do governo afetando, no sentido de Granger, o comportamento do produto. Ainda, observou-se que a causalidade flui de forma bidirecional entre a despesa corrente do governo e o produto, com um nível de significância próximo a 1\%. Em outras palavras, isso significa que o crescimento do produto melhora as despesas correntes do governo e estas, por sua vez, estimulam a produção. Entretanto, não foi possível observar nenhuma direção de causalidade entre o produto e as despesas agregadas com bens de capital do governo, em nenhum grau de significância padrão.

Dado os resultados dos testes de causalidade, investiga-se a relação entre o produto e os gastos públicos estimando as equações (1) e (2). A Tabela 1 apresenta os resultados da estimação da relação de longo prazo entre produto e despesas agregadas públicas de 1980 a 2005 . Como as variáveis, que representam o produto, as despesas correntes e as despesas com capital, são não estacionárias, segue-se a metodologia de Engle e Granger e Johansen.

Tabela 1: Relação de longo prazo do produto e das despesas agregadas públicas no Brasil 1980 a 2005.

\begin{tabular}{lcccc}
\hline Variável & Coef. & Erro-padrão & Estatística $t$ & Prob. \\
\hline C & $9,3288^{*}$ & 0,0495 & 188,2332 & 0 \\
DESCAPY & $0,0274^{* * *}$ & 0,0155 & 1,764 & 0,093 \\
DESCORRY & $-0,0729^{* *}$ & 0,0344 & $-2,1195$ & 0,0467 \\
D94 & $0,0815^{*}$ & 0,014 & 5,808 & 0 \\
D8384 & $-0,0522^{*}$ & 0,0124 & $-4,2057$ & 0,0004 \\
D8687 & $0,0445^{*}$ & 0,0112 & 3,9439 & 0,0008 \\
\hline 0,8811 & AIC $=-5,4426$ & $\mathrm{Q}(20) 21417=$ & $\mathrm{LM}(1)=0,0655$ & $\mathrm{LM}(4)=0,3952$ \\
DW=1,8418 & $\mathrm{SC}=-5,1522$ & $-0,373$ & $-0,8006$ & $-0,809$ \\
White $=0,8567$ & Arch $(1)=0,1880$ & $\mathrm{DF}(1)=-3,4443^{*}$ & $\mathrm{PP}=-4,7746^{*}$ & \\
\multicolumn{1}{c}{$-0,5571$} & $-0,6685$ & & & \\
\hline
\end{tabular}

Nota: Método de estimação por MQO. Matriz de variância e covariâncias corrigidas pelo método de White. ${ }^{* * *}$ significante em $10 \%$, **ignificantes em $5 \%$, *significantes em $1 \%$.

A elasticidade de longo prazo da despesa corrente foi negativa de 0,0729 e estatisticamente significante no nível de $5 \%$. Ou seja, um aumento de $1 \%$ nos gastos com despesa corrente ocasionaria uma redução de $0,07 \%$ do PIB. Ou seja, gastos correntes do governo implicariam redução no produto de longo prazo. Esse fato está de acordo com a literatura, pois esse tipo de despesa não expressa crescimento 
de capacidade produtiva da economia. A estimativa da elasticidade de longo prazo da despesa com capital foi positiva e igual a 0,0274 , mostrando-se estatisticamente significante no nível de $10 \%$. Ou seja, um aumento de $1 \%$ nos gastos com despesa de capital ocasionaria um aumento aproximadamente de $0,03 \%$ do PIB. Novamente, esse resultado está sustentado teoricamente por ser uma variável que contribui para compor o estoque de capital a qual entra na função de produção, implicando aumento no produto marginal do capital privado.

Além disso, foram introduzidas variáveis dummies devido à identificação de alguns fatos econômicos que poderiam estar influenciando o comportamento do produto no período de 1980 a 2005 . As seguintes dummies foram utilizadas:

a) D8384 captura a nova fase da economia brasileira após ter vivenciado um ajuste externo dramático, relativo ao alto endividamento e à escassez de financiamentos internacionais;

b) D8687 tem como finalidade avaliar o choque promovido pela implementação do Plano Cruzado, que teve um efeito efêmero no combate à inflação; ${ }^{7}$

c) D94 procura captar os efeitos da mudança de regime econômico, provocado pela adoção do Plano Real e a consequente redução drástica da inflação e, portanto, a queda no imposto inflacionário. Nota-se que nos três casos as variáveis dummies são altamente significativas o que vem a demonstrar uma boa aderência do modelo às evidências empíricas da economia brasileira.

Em seguida, realizou-se o teste de DF e o teste PP para o resíduo da regressão da equação de longo prazo. Os resultados mostraram que é possível aceitar a hipótese de cointegração entre produto, despesa corrente e despesa com capital, ou seja, as referidas variáveis têm uma tendência comum. Os resultados obtidos na Tabela 1 podem ser interpretados como relações de longo prazo entre as variáveis. Em geral, os testes de diagnósticos mostraram que os resultados da regressão apresentam qualidades estatísticas.

Verificou-se por meio do teste de cointegração de Johansen que as estatísticas do teste de autovalor máximo e do teste "traço" rejeitaram a hipótese de nenhum vetor de cointegração, aceitando a hipótese alternativa de existência de apenas um único vetor de cointegração com nível de significância de $1 \%{ }^{8}$ Tal fato indica a presença de uma relação de equilíbrio de longo prazo entre os produtos e as despesas públicas correntes e com capital. Essa conclusão vem confirmar os resultados obtidos pelo método de Engle e Granger, como mostra a Tabela 1. Desse modo, os resultados encontrados pela metodologia de Engle e Granger podem ser interpretados.

As estimativas da influência da composição dos gastos públicos sobre o produto brasileiro no período de 1980 a 2005 estão reportadas na Tabela 2. Foi estimado um modelo contendo todas as variáveis explicativas, que representam os componentes dos gastos em proporção ao PIB (equação 2), adicionando-se algumas dummies para a identificação da influência de possíveis eventos externos sobre a variável dependente. As variáveis que representam os gastos com educação, com defesa nacional e segurança pública e com assistência social não apresentaram impactos estatisticamente significantes em nenhum dos modelos estimados. Esse resultado é confirmado pelo teste de causalidade que mostra a não causalidade no sentido de Granger da educação e da defesa e segurança nacional sobre o produto. A categoria assistência social mostrou causalidade no sentido de Granger, porém com nível de significância baixo de $10 \%$. O que se pode sugerir é a importância dessa categoria de gastos sobre os gastos totais, pois o mesmo aumentou acentuadamente ao longo do período.

\footnotetext{
${ }^{7} \mathrm{~A}$ década de 80 caracterizou-se por uma profunda crise da economia brasileira, tendo como um dos principais atores o setor governo. Várias medidas fiscais visavam a conter os gastos públicos, as de maiores impactos foram aquelas que procuraram estabilizar a economia, como o Plano Cruzado em 1986, Plano Bresser, 1987, Plano Verão, 1989, e Plano Collor em 1990.

${ }^{8}$ As Tabelas A1 e A2, no Apêndice, contêm os resultados dos testes de cointegração, conforme metodologia de Johansen e Juselius (1990).
} 
Tabela 2: Resultados das regressões do produto em função dos componentes dos gastos públicos em proporção ao PIB, 1980 a 2005.

\begin{tabular}{lcccc}
\hline Modelo 1 & \multicolumn{5}{c}{} \\
\hline 1980 a 2005 & Coef. & Erro padrão & Estatística $t$ & Prob. \\
\hline C & 9,1278 & 0,0305 & 298,696 & 0 \\
COMY & $0,1776^{*}$ & 0,0212 & 8,3562 & 0 \\
SAUSY & $0,1211^{*}$ & 0,0203 & 5,9484 & 0 \\
ENERMY & $-0,0746^{*}$ & 0,0165 & $-4,5191$ & 0,0003 \\
TRANSPY & $0,1026^{*}$ & 0,0251 & 4,084 & 0,0007 \\
D94 & $-0,0605^{*}$ & 0,0157 & $-3,8411$ & 0,0012 \\
D96 & $0,0399^{*}$ & 0,0155 & 2,5656 & 0,0195 \\
D83 & $0,0508^{*}$ & 0,0136 & 3,7227 & 0,0016 \\
\hline 0,8882 & AIC $=-5,3509$ & Q(12)=17,642 & LM(1)=1,0831 & LM(4)=0,9647 \\
DW $=2,21$ & SC $=-4,9638$ & $-0,127$ & $-0,3125$ & $-0,4571$ \\
Arch $(1)=0,6255$ & White $=1,6241$ & DF $=-4,3020^{*}$ & PP $=-6,8551^{*}$ & \\
\multicolumn{1}{c}{$-0,437$} & $-0,1945$ & & & \\
\hline
\end{tabular}

Nota: Método de estimação por MQO. Matriz de variâncias e covariâncias corrigidas pelo método de White. *Significativo a 1\%.

Apenas as variáveis que representam gastos com comunicação, saúde, energia e recursos minerais e transporte mostraram impactos estatisticamente significantes com nível de significância de 1\%. Portanto, foi estimado o modelo 1 da Tabela 2, que é o modelo parcimonioso, apresentando apenas as estimativas das variáveis que mantiveram sua significância estatística. Os sinais dos coeficientes estimados das variáveis componentes dos gastos mostraram empiricamente como esses componentes influenciam o produto. Como as séries temporais em nível são integradas de ordem um, ou seja, I(1), usou-se a metodologia de Engle e Granger para testar a hipótese de cointegração entre essas variáveis.

As elasticidades de longo prazo da despesa com comunicação, saúde e saneamento e transporte mostraram impactos positivos sobre o produto com nível de significância de $1 \%$. Um aumento em $1 \%$ nos gastos com comunicação em proporção ao PIB aumentaria o produto em $0,17 \%$. Já, um aumento de $1 \%$ nos gastos com saúde e saneamento em proporção ao PIB teria um impacto de $0,12 \%$ no produto. Por fim, um aumento de $1 \%$ nos gastos com transporte em proporção ao PIB aumentaria o produto em $0,10 \%$. A direção do sinal está de acordo com a teoria, pois se trata de despesas associadas à infraestrutura e saúde, as quais produzem externalidades positivas ao setor produtivo privado.

Já a elasticidade de longo prazo da despesa com energia e recursos minerais mostrou-se estatisticamente significante no nível de $1 \%$, porém com sinal impreciso, pois o sinal foi positivo no modelo de acordo com a equação (2) e no modelo parcimonioso foi negativo. Isso pode ser uma influência do próprio comportamento da série gastos com transporte, pois essa categoria de despesa mostrou uma tendência decrescente, em grande parte do período analisado, havendo uma leve mudança em meados da segunda metade da década de 90 , quando passa a crescer, porém com taxas cada vez menores.

Ainda, as variáveis dummies mantiveram-se estatisticamente significantes no modelo 1 , indicando a importância dos fatos empíricos mencionados anteriormente no comportamento do produto. Em seguida, realizou-se o teste de DF e o teste PP para o resíduo da regressão da equação de longo prazo. Os resultados mostraram que o produto e os componentes dos gastos públicos cointegram, principalmente, no modelo 1 que reúne apenas as variáveis que mostraram significância estatística. 
Com relação aos testes de diagnósticos, o coeficiente de determinação mostrou um ajuste altamente satisfatório do modelo aos dados. A estatística do teste DW, do teste Q-Ljung-Box e do teste Multiplicador de Lagrange (LM) indicaram para a não autocorrelação dos resíduos. O teste de White também não rejeitou a hipótese nula de ausência de heterocedasticidade. O teste Arch não mostrou indicações de heterocedasticidades condicional auto-regressiva.

De forma a interpretar diretamente as elasticidades de longo prazo, as equações foram novamente estimadas, porém as variáveis explicativas não foram colocadas em proporção ao PIB. Foi estimado o modelo completo, ou seja, com todas as variáveis independentes, conforme equação (2). Novamente, as categorias de gastos públicos educação, defesa nacional e segurança pública e assistência social não mostraram significância estatística. Os gastos com comunicação, saúde e saneamento, energia e transporte permaneceram com impactos positivos e estatisticamente significativos com nível de $1 \%$.

A tabela 3 apresenta os resultados da estimação do modelo parcimonioso. Nesse modelo, todas as categorias de despesas públicas foram estatisticamente significantes e com sinal positivo, exceto a variável despesa com energia e recursos minerais mostrou um sinal negativo. Um aumento de $1 \%$ nos gastos com comunicação tem um impacto de $0,11 \%$ no produto. Um aumento de $1 \%$ nos gastos com saúde e saneamento tem um efeito de $0,12 \%$ no produto e, por fim, um aumento de $1 \%$ nos gastos com transporte tem um impacto de aproximadamente $0,10 \%$ sobre o produto brasileiro.

Tabela 3: Resultados das regressões do produto em função dos componentes dos gastos públicos, 1980 a 2005.

\begin{tabular}{lcccc}
\hline Modelo 2 & \multicolumn{5}{c}{} \\
\hline 1980 a 2005 & Coef. & Erro-padrão & Estatística $t$ & Prob. \\
\hline C & 6,3695 & 0,3703 & 17,197 & 0 \\
COMY & 0,1103 & 0,0118 & 9,3059 & 0 \\
SAUSY & 0,124 & 0,0151 & 8,1785 & 0 \\
ENERMY & $-0,0361$ & 0,0126 & $-2,8664$ & 0,0092 \\
TRANSPY & 0,0992 & 0,0188 & 5,2772 & 0 \\
\hline 0,8136 & AIC $=-5,0699$ & $\mathrm{Q}(12)=16,310$ & $\mathrm{LM}(1)=0,7156$ & $\mathrm{LM}(4)=1,2405$ \\
DW $=1,64$ & $\mathrm{SC}=-4,8280$ & $-0,177$ & $-0,4075$ & $-0,3311$ \\
White $=0,6362$ & $\mathrm{DF}(1)=-4,1712^{*}$ & $\mathrm{PP}=-4,1922^{*}$ & & \\
\multicolumn{1}{c}{$-0,7373$} & & & & \\
\hline
\end{tabular}

Nota: Método de estimação por MQO. Matriz de variância e covariâncias corrigidas pelo método de White. As variáveis encontram-se definidas na seção 2. *Significativo a $1 \%$.

Além disso, observou-se que as despesas com saúde apresentaram um impacto maior sobre o produto, sendo seguidos pelas despesas com comunicação e transporte. As despesas com energia e recursos minerais mostraram um impacto negativo e estatisticamente significativo. Esse resultado revela que houve uma relação negativa entre a categoria de despesas públicas em energia e recursos minerais e o crescimento, ou seja, as variações nas despesas públicas em energia e recursos minerais tiveram efeitos que desestimularam a produção nacional. Esse resultado mostra-se não intuitivo, porém, como mencionado anteriormente, essa categoria de despesa revelou um decrescimento em grande parte do período analisado.

Os resultados dos testes de diagnósticos como, a estatística do teste DW, do teste Q-Ljung-Box e do teste Multiplicador de Lagrange (LM) apontaram também para a não autocorrelação dos resíduos. 0 teste de White também não rejeitou a hipótese nula de ausência de heterocedasticidade. $O$ teste Arch não mostrou indicações de heterocedasticidades condicional auto-regressiva. 
Os testes de DF e PP para os resíduos das regressões da equação de longo prazo mostraram que é possível aceitar a hipótese de cointegração entre produto e os componentes dos gastos públicos. Portanto, os resultados obtidos na tabela 3 podem ser também interpretados como relações de longo prazo entre as variáveis. Para confirmar tais resultados, a Tabela A2, no Apêndice, mostra os resultados do teste de cointegração pela metodologia de Johansen do produto com os componentes dos gastos públicos de 1980 a 2005. Em geral, os resultados confirmam àqueles obtidos pelo método de Engle e Granger, indicando a presença de uma relação de equilíbrio de longo prazo, ou seja, de cointegração, entre os produtos e as categorias de despesas públicas.

A estatística do teste de autovalor máximo e do teste traço dos modelos 1 e 2 rejeitaram a hipótese de nenhum vetor de cointegração, indicando a presença de uma equação de cointegração no nível de $1 \%$ de significância. Em geral, os resultados confirmam àqueles obtidos pelo método de Engle e Granger, indicando a presença de uma relação de equilíbrio de longo prazo, ou seja, de cointegração, entre os produtos e as categorias de despesas públicas. No modelo 2, foram suprimidos os resultados das variáveis dummies D94, D96 e D83 por economia de espaço e por seus valores não variarem significativamente dos valores estimados no modelo 1 .

Em síntese comunicação, saúde e saneamento e transporte foram as categorias de gastos públicos que mostraram relevância empírica na composição das despesas públicas. Em geral, os resultados foram consistentes com os modelos teóricos e com as evidências empíricas, exceto com a categoria de gastos energia e recursos minerais. Os gastos públicos em comunicação, transporte e saúde e saneamento podem ser considerados como gastos produtivos. Para uma dada quantidade de fatores privados, melhores estradas, portos, ferrovias, comunicação, saúde e saneamento implicam uma maior produtividade desses fatores e, consequentemente, elevando o produto final.

\section{CONCLUSÕES}

Os gastos do governo na economia sempre têm tido um interesse especial, sobretudo, nos países de mercados emergentes, os quais necessitam de um crescimento econômico mais acelerado. A visão é que os investimentos públicos em atividade de infraestrutura na provisão de bens e serviços em espaços econômicos de baixa atratividade privada e na formação de capital humano podem ter efeitos positivos sobre o crescimento das economias.

A análise do comportamento dos gastos públicos mostrou que parte significativa das despesas em infraestrutura tem decaído ao longo do período. Apesar da volatilidade, observou-se também que as despesas desagregadas por tipos de gastos em infraestrutura apresentaram, em média, uma tendência decrescente. Ressalta-se que as contradições encontradas com gastos em educação e transporte, relativamente às despesas com assistência e previdência social. A importância da educação sobre o nível de bem estar da sociedade, como fator de redução da pobreza e da desigualdade de renda, é bem estabelecida tanto na academia quanto na sociedade; porém, verificou-se nos últimos anos um decréscimo ainda maior nesse tipo de despesa. A observação da tendência de longo prazo do setor de transporte comprova a deterioração da malha rodoviária brasileira e os baixos investimentos em ferrovias e portos. 0 transporte da produção nacional caracteriza-se por um transporte com elevado custo relativamente a outros países em desenvolvimento, além de apresentar um desperdício no translado, principalmente, da produção agrícola. O comportamento da assistência e previdência social evidencia os déficits contínuos que comprometem parcelas crescentes das despesas totais do governo, sem contrapartida na produção.

Por fim, as despesas públicas em comunicação, transporte, saúde e saneamento mostraram-se como gastos produtivos por estimular o crescimento da renda. Essas categorias de gastos públicos mostraram impactos positivos e estatisticamente significativos no período de 1980 a 2005 . Salienta-se que o artigo mostra uma análise ainda preliminar sobre o comportamento dos gastos públicos, necessitando de uma investigação mais detalhada sobre o comportamento, por exemplo, de cada tipo de gasto, principalmente, em energia. $O$ estudo também pode ser estendido para análise dos efeitos de curto prazo. 


\section{BIBLIOGRAFIA}

Barro, R. J. (1990). Economic growth in a cross-section of countries. The Quarterly Journal of Economics, 106:407-444.

Barro, R. J. \& Martins, X. (1990). Economic growth and convergence across the United States. Technical report, NBER, Cambridge: Massachusetts. National Bureau of Economic Research, Aug. 1990. 59 p. (NBER Working Paper $n^{\circ} 3419$ ).

Cândido, J. \& José, O. (2001). Os gastos públicos no Brasil são produtivos? Planejamento e Política Pública, 23:233-260.

Enders, W. (1995). Applied econometric time series. New York: John Willey \& Sons.

Engle, R. F. \& Granger, C. W. J. (1987). Co-integration and error correction: Representation, estimation, and testing. Econometrica, 55(2):251-276.

Ferreira, P. (1996). Investimento em infra-estrutura no Brasil. Fatos estilizados e relações de longo prazo. Pesquisa e Planejamento Econômico, 26(2):231-252.

Ferreira, P. \& Malliagros, T. (1998). Impactos produtivos da infra-estrutura no Brasil - 1950/95 . Pesquisa e Planejamento Econômico, 28(2):315-338.

Granger, C. W. J., Huang, B. N., \& Yang, C. W. (1998). A bivariate causality between stock prices and exchange rates: Evidence from recent Asia FLU. Technical report, Department of Economics. University of California, San Diego. (Discussion Paper 98-09), 26 p.

Harris, R. I. D. (1995). Using cointegration analysis in econometric modeling. Harvester: Wheatsheaf.

Herrera, S. \& Blanco, F. (2006). The quality of fiscal adjustment and the long run growth impact of fiscal policy in Brazil. In Encontro Nacional de Economia, XXXIV, 2006. Salvador, BA, volume 1, page 21. ANPEC.

Johansen, S. (1988). Statistical analysis of cointegration vectors. Journal of Economic Dynamic and Control, 12:231-254.

Johansen, S. \& Juselius, K. (1990). Maximum likelihood estimation and inference on cointegration With applications to the demand for money. Oxford Bulletin of Economics and Statistics, 52:169-211.

Lledó, V. D. \& Ferreira, P. (1997). Crescimento endógeno, distribuição de renda e política fiscal: Uma análise cross-section para os estados brasileiros. Pesquisa e Planejamento Econômico, 27(1):41-70. Rio de Janeiro: IPEA.

Mazoni, M. G. (2005). Gastos públicos e crescimento econômico no Brasil: Análise dos impactos dos gastos com custeio e investimento. Dissertação de mestrado, FEA/USP, São Paulo. 


\section{A. APÊNDICE}

Figura A-1: Componente de tendência de longo prazo das séries de despesas públicas, no período de 1980 a 2005

Educação

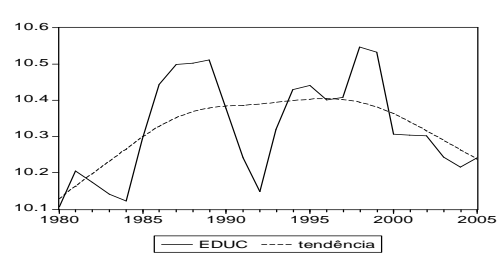

Defesa e segurança

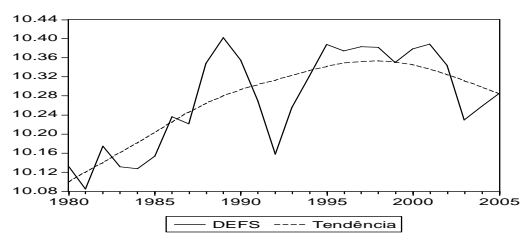

Transporte

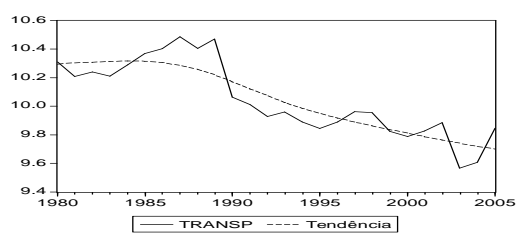

Assistência e previdência

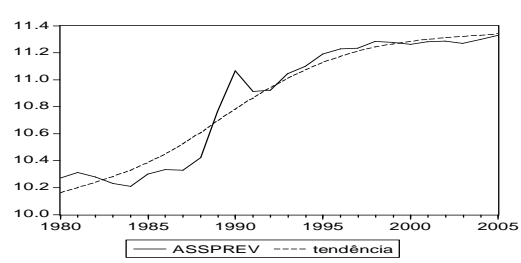

Energia

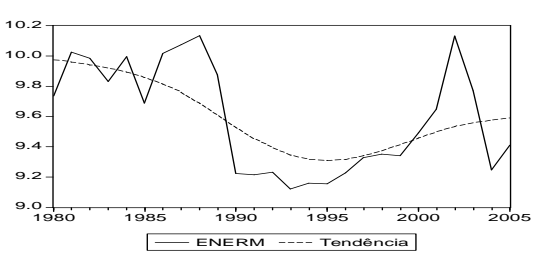

Comunicação

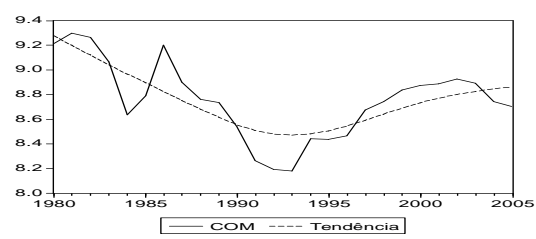

Saúde

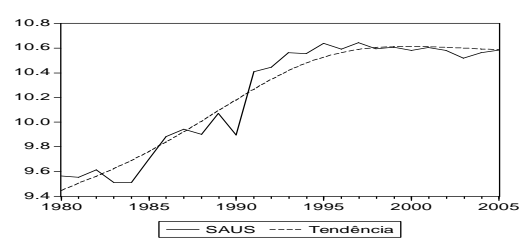

Produto

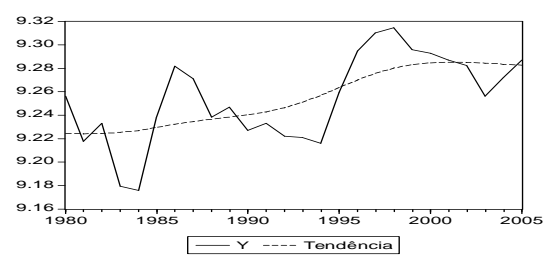


Tabela A-1: Teste de cointegração de Johansen para o produto e as despesas agregadas públicas, 1980 a 2005

\begin{tabular}{c|c|cccc}
\hline & & $\lambda_{\max }$ & V.C & & V.C. \\
Modelo & Def & & $1 \%$ & Traço & $1 \%$ \\
\hline$\Delta(Y)$ & 1 & $32,97^{*}$ & 30,34 & $44,21^{*}$ & 48,45 \\
$\Delta($ descapy $)$ & & 6,21 & 23,65 & 11,24 & 30,45 \\
$\Delta($ descorry $)$ & & 5,02 & 16,26 & 5,02 & 16,26 \\
\hline
\end{tabular}

Nota: $\left.\left({ }^{*}\right),{ }^{* *}\right),\left({ }^{* * *}\right)$ denotam a rejeição da hipótese nula nos níveis de significância de $1 \%$, 5\% e $10 \%$, respectivamente. 0 termo $\alpha$ representa o coeficiente de ajustamento de cada variável endógena do VAR. V.C. é valor crítico. Defasagem segundo critérios SBC e AIC. As variáveis encontram-se definidas na seção 3.

Tabela A-2: Teste de cointegração do produto e dos componentes dos gastos públicos

\begin{tabular}{c|c|cccc}
\hline & & $\lambda_{\max }$ & V.C & & V.C. \\
Modelo 2 & Def & & $1 \%$ & Traço & $1 \%$ \\
\hline$\Delta($ comy $)$ & 1 & $41,07^{*}$ & 39,79 & $85,96^{*}$ & 84,45 \\
$\Delta($ enermy $)$ & & 16,5 & 33,24 & 44,89 & 60,16 \\
$\Delta($ sausy $)$ & & 12,13 & 26,81 & 28,39 & 41,07 \\
$\Delta($ transpy $)$ & & 9,26 & 20,2 & 16,25 & 24,6 \\
\hline & & 6,98 & 12,97 & 6,98 & 12,97 \\
\hline Modelo 4 & Def & $\lambda_{\max }$ & V.C & & V.C. \\
$\Delta$ (comy $)$ & 1 & $41,07^{*}$ & 39,79 & $85,96^{*}$ & 84,45 \\
$\Delta($ enermy $)$ & & 16,5 & 33,24 & 44,89 & 6016 \\
$\Delta($ sausy $)$ & & 12,13 & 26,81 & 28,39 & 41,07 \\
$\Delta($ transpy $)$ & & 9,26 & 20,2 & 16,25 & 24,6 \\
\hline
\end{tabular}

Nota: $\left.\left({ }^{*}\right),{ }^{(*)}\right),\left(^{* * *}\right)$ denotam a rejeição da hipótese nula nos níveis de significância de $1 \%, 5 \%$ e $10 \%$, respectivamente. Defasagem segundo critérios SC e AIC. O desvio padrão $t$ está entre parênteses. 